\title{
Stability of Tailings Beach Slopes
}

\author{
S. Barrera Tailings Dam Consultant, ARCADIS Geotecnica, Chile \\ C. Riveros Tailings Transport, ARCADIS Geotecnica, Chile
}

\section{INTRODUCTION}

The technology of paste and thickened tailings allows for the disposal of tailings with a much steeper slope than that of conventional tailings. This characteristic together with a proper tailings management allows for tailings storage with a much smaller dam and, therefore, lower costs.

Obviously this greater storage capacity for a smaller dam represents an advantage as long as the deposited tailings are stable with time. It is in this aspect where the tailings characteristics and geotechnical behaviour of the paste and thickened tailings are relevant to estimate and assure the tailings stability. This is especially critical in areas of high seismicity and/or intense rainfalls.

It should be noted that some aspects of the behaviour of conventional tailings (the product from flotation whose slurry has a Newtonian hydraulic behaviour) has not received much attention, and, in particular, its mechanical residual strength has been disregarded in most of the stability analysis of tailings dams. The evidence that the tailings may achieve steeper slopes than those assumed by general practice and the advantages that this entails have made it necessary to analyze in greater detail the strength of this material.

However, this lack of knowledge is valid for the behavior of tailings beaches subjected to intense precipitation. With tailing beach slopes less than $0.5 \%$, the subject of tailings displacement by rains and the subsequent erosion was not relevant, particularly when the beaches are small in area. But the application of this thickening technology to impoundments with surfaces greater than 100 or 200 ha could imply the eventual removal of 1 to 2 millions of cubic meters $\left(\mathrm{Mm}^{3}\right)$ only as a consequence from a $100 \mathrm{~mm}$ precipitation, if the tailings do not present cohesion or a matrix that allows it to resist the erosion forces of the surface runoff.

Given that this technology has been applied very recently, there is very little experience of the real behavior of the thickened or paste tailings and these tailings may, once deposited, present a different behavior than conventional tailings.

The objective of this paper is to characterize this material based on available information and studies as well as to propose some methodology to estimate the stability of the beaches of the tailings impoundments.

\section{BACKGROUND}

In Barrera (2005), a comparative analysis was presented of the effect on the deposited tailings between conventional and thickened tailings. Several of the observations are based on estimates and laboratory tests 
since the available information is scarce. What follows is a characterization of the deposited tailings based on the main parameters that determine its stability behavior, including grain size and specific gravity, deposition density, deposition slope, strength parameters, and ultimate strength.

\subsection{Grain size and specific gravity}

As far as grain size and specific gravity are concerned, the thickening process does not imply any change in the tailings particles, therefore, these parameters remain unchanged throughout the tailings transport system. One should not discard the effect that in some cases is generated by the presence of flocculants to the thickening process on the tailings behavior. These mainly affect the transport and not its disposal, since in fact its effect will disappear during the transport.

However, from a deposition point of view, the grain size distribution of the tailings throughout the discharge is different in accordance to the solids content of the tailings slurry. The segregation is stronger or weaker depending on the level of solids content, giving rise to a slope generally concave (Blight, 1987). In the case of thickened and paste tailings, this segregation is practically non-existent, which translates into a constant slope.

\subsection{Deposition density}

One of the ways used to estimate this density is the sedimentation test. This test is not standardized but is widely used and consists in measuring the level of decanted solids in a test tube after a predetermined period. Another test used to estimate the tailings deposited density is the Rowe cell test. This test allows us to have a better approach because it is including the consolidation effect.

In this area, there is the impression and consensus that the initial dry density of the tailings would increase together with the slurry solids content. Some of the data published to date seem to corroborate this impression but the data is still scarce and does not allow for the extrapolation to the real value in the newly deposited impoundment. In fact, the value that the density reaches is also a function of geotechnical variables and dry-wet cycles. Moreover, if the behaviour of consolidation of a material is analyzed, we can conclude that this difference in density values would only be valid within a certain range of pressures but, once the preconsolidation pressure is surpassed, should tend to a similar final value.

It is interesting to analyse the field density results in the tailings impoundment of Bulyanhulu (Theron et al., 2005). This mine produces 65000 tpm that discharges its tailings as paste with a solids content between $73 \%$ and $79 \%$. The average tailings has a $78 \%$ portion that passes the $\# 200$ sieve and a $15 \%$ of clay $(<2 \mu \mathrm{m})$. The average density values measured at several distances from the discharge show that the density increases with time until it levels off as shown in Table 1.

The values for initial voids ratio (day 0 ) are about 0.70 to 0.65 (extrapolated from Figure 3 of op cited), values which are much lower than the average values of 1.00 measured in conventional copper tailings 
(Barrera, 1998). This information would confirm the thesis that the thickened and paste tailings reach higher densities than conventional tailings. In any case this data does not allow us, at present time, to predict the density of deposition of thickened and conventional tailings in a reliable way. In the case of thickened tailings and given that there is only limited experience to date, the tests at pilot scale seem to be the best way of predicting a density value.

\section{Table 1 Density of deposited tailings in Bulyanhulu (Theron et al., 2005)}

\begin{tabular}{|c|c|c|}
\hline Time (day) & $\mathbf{1}^{\mathbf{1}}$ & $\mathbf{e}^{\mathbf{3}}$ \\
\hline 30 & 1.69 & 0.633 \\
\hline 60 & 1,74 & 0.586 \\
\hline 89 & 1,83 & 0.508 \\
\hline 101 & 1,85 & 0.492 \\
\hline
\end{tabular}

${ }^{1}$ Time elapsed since tailings discharge

${ }^{2}$ Dry density

${ }^{3} \mathrm{e}=$ void ratio for specific gravity of 2.76

\subsection{Deposition slope}

The tailings deposition slope is a key parameter in the estimation of the storage capacity of an impoundment. In recent years, a series of authors have dealt with the subject of trying to predict the value of the slope as a function of the tailings characteristics (among others, grain size, solids content, rheology, flow, etc.). There is no single theory to date that unifies all the parameters involved and some of the formulas available are only applicable to a specific range and do not allow for their extrapolation outside of this range. Table 2 is a list of average values in large impoundments in Chile.

Table 2 Deposition slope in Chilean impoundments

\begin{tabular}{|c|c|c|c|c|c|c|}
\hline \multirow[b]{2}{*}{ Impoundment } & \multirow[b]{2}{*}{$\mathbf{G}$} & \multirow[b]{2}{*}{$\begin{array}{c}C_{w} \\
(\%)\end{array}$} & \multirow[b]{2}{*}{$\begin{array}{c}d_{50} \\
(\mu \mathrm{m})\end{array}$} & \multirow{2}{*}{$\begin{array}{c}\text { Beach } \\
\text { Slope } \\
(\%)\end{array}$} & \multicolumn{2}{|c|}{ Total Tailings } \\
\hline & & & & & $\begin{array}{c}\text { Production } \\
\text { (tpd) }\end{array}$ & $\begin{array}{l}\text { Flow } \\
\left(\mathrm{m}^{3} / \mathrm{s}\right)\end{array}$ \\
\hline Pampa Pabellon & 2.70 & 50 & 52 & 0.50 & 110000 & 1.74 \\
\hline Tranque Austral & 2.70 & 35 & 119 & 0.35 & 33000 & 0.85 \\
\hline Talabre & 2.75 & 53 & 70 & 0.30 & 182000 & 2.63 \\
\hline Las Tortolas & 2.80 & 26 & 75 & 0.60 & 56000 & 2.08 \\
\hline El Torito & 2.67 & 20 & 10 & 0.30 & 20000 & 1.01 \\
\hline Laguna Seca & 2.63 & 51 & 60 & 0.30 & 235000 & 3.65 \\
\hline Tranque $\mathrm{N}^{\circ} 4$ & 2.67 & 33 & 10 & 0.60 & 12000 & 0.33 \\
\hline Caren & 2.70 & 45 & 51 & 0.18 & 147000 & 2.71 \\
\hline
\end{tabular}

G: Specific gravity

$\mathrm{C}_{\mathrm{w}}$ : Solids content

$\mathrm{d}_{50}$ : Diameter in $\mu \mathrm{m}$ of particles under $50 \%$

For the case of thickened tailings, there aren't enough statistics of real projects due to the few cases available. At the mine Bulyanhulu (Shuttleworth et al., 2005), values for slope of deposited tailings in beaches that range between $8.3 \%$ and $7.1 \%$ are presented, depending on the thickness of the tailings layer. In this case, the discharge flow is $80 \mathrm{~m}^{3} / \mathrm{hr}$. It is known that with less flow, the deposition slope increases and 
all the existing formulas show this. But these formulas are calibrated for cases with much smaller solids contents, which may not be extrapolated.

A conclusion from the above experience is that a more concentrated tailings sample would allow for a greater slope in the tailings beach (as compared to a less concentrated sample). But it is also necessary to include in the analysis all the aspects related to the environment and drainage conditions. Based on the above we can expect that this is an aspect that requires a case by case analysis.

Laboratory tests to date do not allow us to predict this beach slope on deposition. Until 2000, traditional tests only allowed us to determine the shape of the beach. Sofra and Boger (2001) proposed laboratory tests that integrate the components that govern this phenomenon: rheology and hydraulics. This approximation that considers the rheology of the tailings slurry is valid for materials with a constant rheology or do not experience changes in their structure during the deposition process.

\section{$2.4 \quad$ Strength parameters}

Shear strength parameters of soil samples depend mainly on the dry density and the level of saturation. This is valid for static and seismic loads. Therefore, the strength of a sample of tailings would only be different if the deposition density and the level of saturation are different for different solids content.

In this aspect, the deposition scheme plays a very important role since it may only strongly influence the density and the moisture content of the deposited tailings. There are very interesting experiences that show the above. For example, those cases with a rapid rate of growth do not allow the deposited tailings to dry surficially nor consolidate when the next layer is already being deposited. In this case, the density is the lowest possible and the saturation is complete, and this situation will be maintained for as long as the tailings permeability characteristics and the impoundment drainage characteristics indicate it. But everything seems to indicate that this difference only occurs in the upper strata (horizons) of the impoundment.

The value of the ultimate strength is key in estimating the stability of a slope in the post-seismic analysis. Studies by Verdugo and Ishihara (1993), indicate that for silty sands, placed without compaction, the ultimate strength (assuming low angle of friction) is within the following range:

$$
\mathrm{S}_{\mathrm{u}} / \sigma_{\mathrm{o}}{ }^{\prime}=<0.086-0.181>
$$

In which, $S_{u}$ is ultimate strength, and $\sigma_{o}{ }^{\prime}$ is effective initial vertical confining stress.

\section{STABILITY ESTIMATE APPROACH}

\subsection{Geotechnical approach}

From a geotechnical point of view, the calculation methods for the analysis of slope stability may be classified into two groups: 
a) Limit analysis methods: The development of this stability analysis and of the limit analysis method experienced an important surge given the complete formulation of the plastic theory and the development of computers. Its application in practice still presents certain degree of complexity since it requires the application of finite element or finite difference methods, but allows for the calculation of deformations as well as stresses, bearing in mind the material's behaviour.

b) Limit equilibrium methods: These are the methods most commonly used in practice for the calculation of slope stability and are fundamentally based on plastic equilibrium limit.

From the point of view of stability analysis of a tailings impoundment, we can identify two critical sections, which may be evaluated independently:

i) Stability of the embankment dam (in conjunction with the tailings deposited).

ii) Stability of the tailings beach (infinite slope).

\subsubsection{Embankment dam}

The stability of an embankment dam in the tailings impoundment (whether conventional or thickened) is determined by applying traditional stability methods of analysis used in the study of dams. The only difference (with regards to conventional tailings impoundments) is that, in the case of thickened tailings, the characteristics of stress deformation of its behavior under loads are included. This type of analysis is common practice in the design of dams and most of the technical texts give details how to apply it to the specific cases.

\subsubsection{Tailings beach or infinite slope}

The failure of infinite slopes corresponds to sliding on a relatively shallow plane, parallel to a long slope. Frequently, it is an underlying layer of greater strength or better mechanical properties that limits the movement to a horizontal failure plane. In general, the curve effects for both lower and upper extremes of the slope are discarded, as well as the lateral surface, so the analysis of the slope is transformed in a twodimensional problem, independent of the height of the slope. This type of slope instability is usually presented in materials with little cohesion.

This is particularly valid in impoundments where maximizing water reclaim leads to depositing tailings in separate compartments to reduce the evaporation areas. In this way, the tailings have time to dry and improve their density and strength properties before receiving a new layer.

On the other hand, the growth of the impoundments generally allows for the consolidation process to favor an improvement in strength properties of the deeper tailings, making the shallower layer more susceptive to instability due to seismic events. 


\subsubsection{Assumptions for the stability analysis}

The stability analysis for infinite slopes assumes that the sliding mass is comprised of a homogeneous soil whose density and shear strength parameters (c: cohesion, $\phi$ : internal friction angle, $\mathrm{S}_{\mathrm{u}}$ or $\mathrm{C}_{\mathrm{u}}$ : shear strength in undrained conditions) are constant along the slope.

In the case of tailings beaches, this material usually presents a high fines content, low density, high saturation, and low cohesion. A material with these conditions is very sensitive to seismic events, liquefying and reducing significantly its shear strength.

The assumptions for this method are applied particularly well for the case of thickened tailings since this type of tailings does not experience segregation along the extension of the beach.

Given that seismic events are of short but intense duration and that during this period a significant change in tailings properties is generated, particularly reducing their strength which is prolonged for a long period after the seismic event has finished, an undrained, static stability analysis that considers the ultimate strength of the material is applied.

Undrained infinite slope - this analysis assumes that the slope considered is saturated. For a prism element as the one considered in Figure 1, the force that triggers the potential failure surface is given by:

$$
\mathrm{T}=\mathrm{W} \cdot \sin \beta=\mathrm{y} \cdot \text { h.b. } \sin \beta
$$

where the shear strength is given by:

$$
R=S_{u} \cdot b / \cos \beta
$$

The Factor of Safety (FS) is obtained by:

$$
\mathrm{FS}=\frac{2 \cdot \mathrm{S}_{\mathrm{u}}}{\gamma \cdot \mathrm{h} \cdot \sin 2 \beta}=2\left(\mathrm{~S}_{\mathrm{u}} / \sigma_{0}^{\prime}\right) / \sin 2 \beta
$$

In which: $S_{u}=$ ultimate strength, $\beta=$ slope angle, and $\gamma^{*} h=\sigma_{o}$ ' is the initial vertical confining stress.

This expression of FS is applicable to thickened or paste tailings because the tailings do not segregate and, therefore, the material is essentially homogeneous. According to this expression, the stable slope (FS=1.0) of the tailings beach is tabulated for different values of $\mathrm{Su} / \sigma_{\mathrm{o}}$ '. 


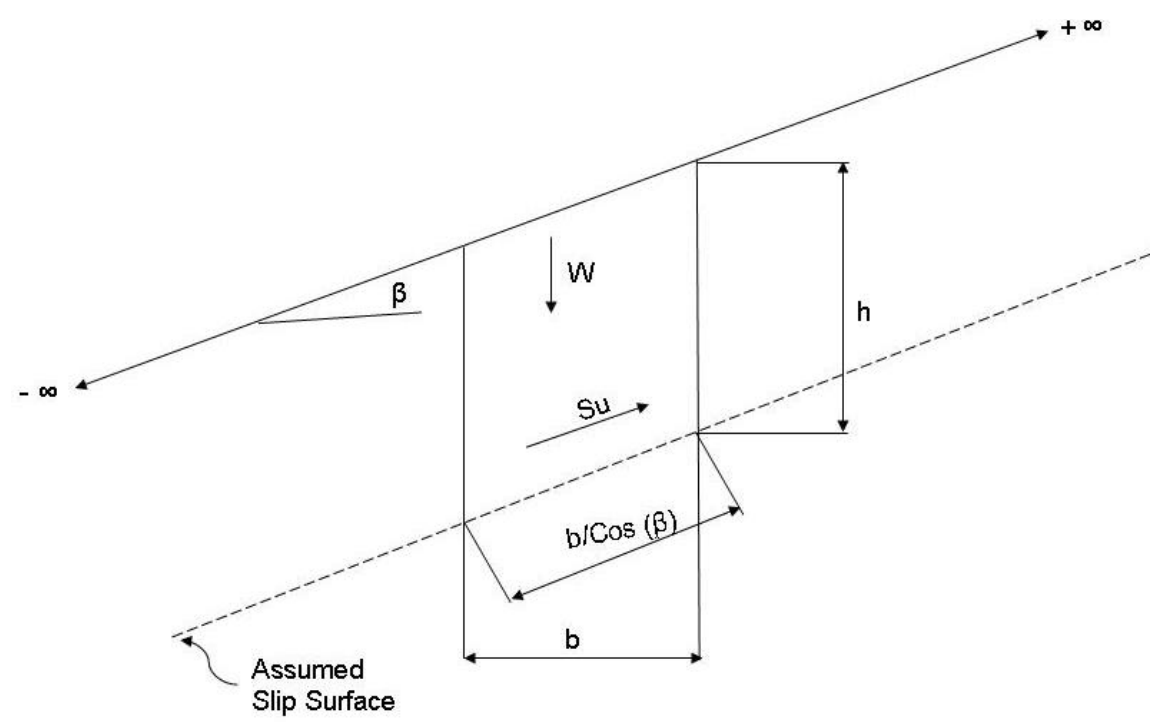

\section{Figure $1 \quad$ Infinite slope}

Table 3 Relationship between ultimate strength and infinite beach slope

\begin{tabular}{|l|l|l|l|l|l|}
\hline $\mathbf{S u} / \boldsymbol{\sigma}_{\mathbf{0}}{ }^{\prime}$ & $\tan \boldsymbol{\beta}$ & $\mathbf{S u} / \boldsymbol{\sigma}_{\mathbf{0}}{ }^{\prime}$ & $\tan \boldsymbol{\beta}$ & $\mathbf{S u} / \boldsymbol{\sigma}_{\mathbf{0}}{ }^{\prime}$ & $\tan \boldsymbol{\beta}$ \\
\hline 0.002 & 0.002 & 0.03 & 0.030 & 0.09 & 0.091 \\
0.004 & 0.004 & 0.04 & 0.040 & 0.1 & 0.101 \\
0.006 & 0.006 & 0.05 & 0.050 & 0.2 & 0.209 \\
0.008 & 0.008 & 0.06 & 0.060 & 0.3 & 0.333 \\
0.01 & 0.010 & 0.07 & 0.070 & 0.4 & 0.500 \\
0.02 & 0.020 & 0.08 & 0.081 & 0.5 & 1.000 \\
\hline
\end{tabular}

\subsection{Rheological approach}

The stability of thickened tailings, analyzed from a rheological point of view, is an aspect that has only recently been explored. In fact, the tailings stability has been focused, until now, mainly from a geotechnical point of view (soil mechanics).

Thickened tailings correspond to more viscous fluids than conventional tailings and therefore present a higher yield stress. In addition, thickened tailings do not separate once deposited, contrary to conventional tailings. These aspects allow us to expect that the thickened tailings, when subjected to a seismic event, would be more stable than conventional tailings considering an equal deposition slope. However, the stability analysis that applies geotechnical methods only considers the density implicitly, does not differentiate between thickened and conventional tailings, and, therefore, does not include the rheological characteristics which are the aspects that allow us to expect that these tailings are more stable.

All of the above has presented the query of how to analyze the stability of thickened tailings using a rheological estimate. This paper presents methodological notions to analyze the stability of tailings considering rheological aspects. 
This methodology only needs to know the moisture content of the deposited tailings (not the density). To determine the moisture contents is easier and cheaper than the deposited density. This is the main advantage of this method.

The rheological notions presented in this chapter are applicable only for the instability of the tailings produced from the occurrence of a seismic event and does not consider any instability generated by extreme precipitation. We consider as a base criterion that, under the occurrence of a seismic event, liquefaction of the deposited tailings occurs and, as a consequence, we will estimate the flow velocity of the tailings removed and their displacement. Because this is a rheological approach pore pressures in tailings is not considered in the analysis.

For a specific tailings, we may know its rheological characteristics by performing tests that allow us to construct its rheological curves, this is shear stress $(\tau)$ versus shear rate $(\dot{\gamma})$, from which we may know yield stress $\left(\tau_{y}\right)$ and the plastic viscosities, parameters that are related to the solids content, mineralogy, clay content, and $\mathrm{pH}$ of a specific tailings.

Once the tailings have been discharged to an impoundment, their rheological characteristics are modified. The tailings, once discharged in the impoundment, releases an amount of water, increasing its solids content and gaining a greater density as compared to the one it had when it was being transported. This change affects its rheological characteristics. Therefore, any stability analysis that is performed on the thickened deposited tailings must consider the new rheological characteristics of the deposited tailings.

To analyze the stability of deposited tailings that are liquefied during a seismic event, we present a first methodological approximation that enables a first estimate of the velocity and displacement of the fluid mass:

i) Estimate of the solids content of the deposited tailings.

Considering that the deposited tailings, susceptible to liquefaction due to a seismic event, are saturated, its solids content may be calculated using the typical formula of soils mechanic as follows:

Determination of the saturation moisture $\left(\omega_{\text {sat }}\right)$ of the deposited tailings as

$$
\omega_{s a t}=\frac{\gamma_{w}}{\gamma_{d}}-\frac{1}{G}
$$

Where, $\omega_{\text {sat }}=$ saturation moisture, $G=$ specific gravity, and $\gamma_{d}=$ dry density.

$G$ is obtained from laboratory tests and $\gamma_{d}$ is determined by field tests.

Determination of the solids content of the liquefied tailings. For this, we replace the water deduced from the saturation moisture in the formula for the solids content; this is: 


$$
C_{W}=\frac{W_{s}}{W_{w}+W_{s}} \text { or } C_{W}=\frac{1}{1+\frac{W_{w}}{W_{s}}}
$$

Where, $C_{W}=$ solids content of deposited tailings, $W_{w}=$ water weight, and $W_{s}=$ solid weight

In addition, we know that moisture is given by:

$$
\omega_{s}=\frac{W_{w}}{W_{s}}
$$

Therefore:

$$
C_{W}=\frac{1}{1+\omega_{\text {sat }}}
$$

ii) Estimate of the rheological and sedimentation characteristics of the deposited tailings

To this end, we consider two types of tests:

- Rheological tests to obtain the curve $\tau$ vs $\dot{\gamma}$ of the deposited tailings performed for a range of solids content values that covers the saturation moistures (densities) measured in the area of the impoundment being analyzed, using the formula (4). As a result of the rheological curves, the yield stress $\left(\tau_{y}\right)$ is determined.

- Sedimentation tests for the values in solids content defined in the preceding rheological tests. This test determines the sedimentation velocity of the slurry.

iii) Stability of the deposited tailings

In countries with seismic events where there are also large tailings impoundments, the phenomenon of tailings liquefaction is a subject that has been analyzed but there aren't enough cases of analysis during the seismic event. The evidence indicates that the liquefaction of the tailings is largely produced in the surficial layers and that it does not necessarily extend to the full extent of the impoundment. Given that the deeper layers are more confined and at a greater density, they are less likely to liquefy. Therefore, it is estimated that the thickness liquefied fluctuates between 1 and $3 \mathrm{~m}$ in typical conditions. But this thickness may be different depending on the conditions of growth and tailings disposition.

The tailings that are liquefied due to seismic events will be maintained in suspension during the event and for a certain period after the event. In this period of suspension (or liquefaction), the tailings may be displaced over the tailings that have not liquefied, with a certain velocity that depends on the rheological characteristics and the type of runoff, until it sediments once again. Both the displacement and the velocity may be estimated from the following approximations:

- The slope of the deposited tailings is a known fact that may be obtained from surveying in case of an existing impoundment. In case the estimate of the expected slope is required at the design stage, we 
can consult the method of Sofra and Boger (2001), which relates the $\tau_{y}$ with the angle of deposition. The liquefied tailings have a larger solids content and, therefore, a larger $\tau_{y}$ than the tailings that were discharged in the impoundment. Consequently, to move the deposited tailings requires more energy than it originally had when being discharged and resulted in the deposited slope. This energy may only be obtained during the period of movement provoked by the seismic event and not once the event is over.

- The flow velocity may be obtained from the following parameters:

- Slope: It is assumed that the removed tailings will flow over a base with a slope that will correspond to the lower tailings layers that were not liquefied and may be estimated as explained in the paragraph above.

- Rheological curves: Knowing the curves $\tau$ v/s $\dot{\gamma}$, it may be determined whether the tailings correspond to a Bingham plastic or another Newtonian behaviour.

- Flow area: Different than a tailings that has been transported through a pipe or channel, in this case we do not know the geometry of the duct through which the tailings will flow, but we may know the approximate flow height and we may consider that this height is applied to the entire tailings beach or we may do the analysis by unit of width.

- Model for head loss: Once the tailings behavior and the geometric characteristics through which it will flow are known, we may apply some known formulas developed by authors such as Wilson and Thomas (1985).

- Velocity: With the information above, the velocity of the liquefied tailings is calculated.

- The displacement of the liquefied tailings may be estimated from the following parameters:

- From the sedimentation tests that were indicated in section ii and with an estimate of the thickness of the layers of liquefied tailings, we can estimate the time it will take for the tailings to sediment again.

- With the flow velocity and the sedimentation time, we can estimate the length of displacement of the liquefied tailings.

\section{CONCLUSIONS}

- To identify the stability of the surface or beach of a tailings impoundment, we have identified two types of analysis:

- Geotechnical method of post-seismic infinite slope with ultimate strength of the tailings, and

- Rheological method with estimate of the yield stress of the liquefied tailings. 
- From a geotechnical point of view, there is available information on the ultimate strength of materials similar to tailings that would allow for the conclusion that tailings beaches with a slope of less than $8 \%$ are stable under a seismic event.

- From a rheological point of view, we may also conclude that the yield stress of the deposited tailings is greater than that of the tailings slurry that generated the slope of the surface. According to this, a seismic event that would liquefy the tailings would only have energy to eventually generate a displacement of the liquefied tailings during the duration of the seismic event. But once concluded the event, there would not be enough energy to continue with the displacement.

- Given this importance, it is necessary to verify the ultimate strength or yield stress of the tailings in representative locations and depths of the impoundment to assure minimum stability. In both cases, we suggest that this estimate of strength parameters comprise the entire range of density of the deposited tailings.

\section{REFERENCES}

Barrera, S. (1998) Deposition densities of tailings in Chilean deposits, Tailings and Mine Waste '98, Colorado. USA.

Barrera, S. (2005) Aspects to be considered in dynamic stability analysis, Thickened Tailings and Paste Seminar, Santiago, Chile.

Blight, G. (1987) The concept of the master profile for tailings dam beaches, International Waste Management Conference, Johannesburg, South Africa.

Shuttleworth, J.C., Thompson, B.J. and Wates, J.A. (2005) Surface paste disposal at Bulyanhulu - practical lesson learned, Proceedings of the International Seminar on Paste and Thickened Tailings, Santiago, Chile.

Sofra, F. and Boger, D. (2001) Slope prediction for thickened tailings and pastes, Tailings and Mine Waste '01, Colorado, USA.

Theron, M., Addis, P.C., Wates, J.A. and Martin, V. (2005) Bulyanhulu mine (Tanzania) paste tailings facility: relating the unsaturated properties of gold tailings to rate of rise, Proceedings of the International Seminar on Paste and Thickened Tailings, Santiago, Chile.

Verdugo, R. and Ishihara, K. (1993) Undrained response of silty and sandy soils, Tercer Congreso Chileno de Ingeniería Geotécnica, La Serena, Chile.

Wilson, K.C. and Thomas, A.D. (1985) A new analysis of the turbulent flow of non-Newtonian fluids, Can J Engng, 63, pp. 539-546. 